\title{
Differences in the pressures of canal anal and rectal sensitivity in patients with fecal incontinence, chronic constipation and healthy subjects
}

\author{
C. Ciriza-de-los-Ríos ${ }^{1}$, A. Ruiz-de-León-San-Juan², M. Díaz-Rubio-García², E. Tomás-Moros³ , F. García- \\ Durán $^{3}$, T. Muñoz-Yagüe ${ }^{1}$, F. Canga-Rodríguez-Valcárcel ${ }^{1}$, A. Gómez-de-la-Cámara ${ }^{1}$ and G. Castellano- \\ Tortajada ${ }^{1}$
}

${ }^{1}$ Hospital Universitario 12 de Octubre. ${ }^{2}$ Hospital Universitario Clínico San Carlos. ${ }^{3}$ Hospital de Fuenlabrada. Madrid, Spain

\begin{abstract}
Introduction: There exits a great variability in the manometric findings between patients with anal incontinence (AI) and healthy subjects. The correlation between the pressures of the anal canal and the $\mathrm{AI}$ is not exact by the wide rank of normal values.

Objectives: Prospective study to evaluate differences in the pressures of the anal canal and in rectal sensitivity in patients with $\mathrm{AI}$, chronic constipation (CC) and healthy subjects.

Material and methods: Ninety four patients with AI, 36 patients with CC and 15 healthy subjects were included. The following data were obtained: age, sex, resting pressure, anal canal length (ACL), squeeze maximum pressure (SMP), squeeze pressure duration (SPD), first sensation, urge and maximum tolerated volume (MTV). Statistical study: test of Kruskal-Wallis, test of Mann-Whitney, and multinomial logistic regression test.

Results: There were significant differences in the resting pressure $(p<0.001)$, the ACL $(p<0.001)$ and the SMP $(p<0.01)$ in the group of $\mathrm{AI}$ with respect to the other two groups. The volume for the first sensation was significantly lower in the healthy subjects than that in the other two groups ( $p<0.05)$. The urge volume and the MVT were smaller in the group with $\mathrm{AI}$ with respect to the other groups $(\mathrm{p}<0.001)$. In multivariate analysis the age, the resting pressure and the volume for the first sensation and urge increase the relative risk for $\mathrm{AI}$.

Conclusions: The greater age, the decrease in anal canal resting pressure and the alteration of rectal sensation increase the risk for $\mathrm{AI}$
\end{abstract}

Key words: Incontinencia fecal. Manometría ano-rectal. Presiones del canal anal. Sensibilidad rectal.

Received: 04-11-09.

Accepted: 20-04-10

Correspondence: Constanza Ciriza de los Ríos. Servicio de Aparato Digestivo. Hospital Universitario 12 de Octubre. Avda. Córdoba, s/n. 28041 Madrid. e-mail: constanzacarpa@gmail.com

\section{RESUMEN}

Introducción: Existe gran variabilidad en los hallazgos manométricos entre pacientes con incontinencia anal (IA) y sujetos sanos. La correlación entre las presiones del canal anal y la IA no es exacta por el amplio rango de valores normales.

Objetivos: Estudio prospectivo para evaluar diferencias en las presiones del canal anal y en la sensibilidad rectal en pacientes con IA, estreñimiento crónico (EC) y sujetos sanos.

Material y métodos: Noventa y cuatro pacientes con IA, 36 pacientes con EC y 15 sujetos sanos. Se obtuvieron: edad, sexo, presión de reposo, longitud del canal anal (LCA), presión de máxima contracción voluntaria (PMCV), duración de la contracción voluntaria, primera sensación, sensación de urgencia y máximo volumen tolerado (MVT). Estudio estadístico: test de Kruskal-Wallis, test de Mann-Whitney, regresión logística multinomial.

Resultados: Se encontraron diferencias significativas en la edad ( $p<0,001)$, la presión de reposo ( $p<0,001)$, la LCA ( $p<$ $0,001)$ y la PMCV $(p<0,01)$ en el grupo de IA con respecto a los otros dos grupos. El volumen para la primera sensación fue significativamente más bajo en los sujetos sanos que en los otros dos grupos $(p<0,05)$. El volumen de urgencia y el MVT fueron menores en el grupo con IA con respecto a los otros dos grupos $(p<$ 0,001). En el análisis multivariante la edad, la presión de reposo y el volumen de la primera sensación y de la urgencia aumentan el riesgo relativo de IA.

Conclusiones: La mayor edad, la disminución presión basal del canal anal y la alteración del umbral sensorial rectal aumentan el riesgo de IA.

Palabras clave: Incontinencia fecal. Manometría anorectal. Presiones del canal anal. Sensibilidad rectal.
Ciriza-de-los-Ríos C, Ruiz-de-León-San-Juan A, Díaz-RubioGarcía M, Tomás-Moros E, García-Durán F, Muñoz-Yagüe T, Canga-Rodríguez-Valcárcel F, Gómez-de-la-Cámara A, Castellano-Tortajada G. Differences in the pressures of canal anal and rectal sensitivity in patients with fecal incontinence, chronic constipation and healthy subjects. Rev Esp Enferm Dig 2010; 102: 683-690. 


\section{INTRODUCTION}

Anal incontinence (AI) is one of the most devastating physical disabilities as it has an important impact in the quality of life (1) .

Although the incontinence concept is very intuitive, there is no unanimously accepted definition of this, with considerable differences according to the different groups. One of the definitions with greater consensus is to consider it as the involuntary, continuous or recurrent loss of faecal content ( $>10$ millilitre) during at least a month in a person older than 3 years (2). However, the term faecal incontinence is used frequently by the clinicians in the case of the incontinence to gas. The term of $\mathrm{AI}$ includes the uncontrolled gas escape, liquid or solid faeces. Therefore, both definitions can be used and at the time of analyzing the different studies it is observed that there is no standard definition (2). It is important to differentiate if the patient presents passive or urge AI. Urge $\mathrm{AI}$ is defined as the loss of faecal material in spite of active attempts to retain the intestinal content. On the contrary, passive AI is the involuntary or unconscious loss of faecal content. Although both groups can sometimes overlap (mixed AI), the clinical differentiation can orient which is the predominant pathophysiological mechanism.

The AI is a very frequent pathology, the frequency considered in the general population being 2-3\%, although the studies of prevalence in the general population show a great variability (3).

The functional chronic constipation (CC) is a pathology defined according to the Rome II and Rome III criteria (4). The prevalence of functional CC varies according to the different definitions and studied populations; it has been indicated that up to $25 \%$ of the general population is considered constipated. In addition, it increases with age and it is more frequent in women than in men (5).

The ano-rectal manometry is an established diagnostic method for the study of both the AI and the CC. Nevertheless, great variability in the manometric findings between patients with AI and in healthy subjects exists (6). The normal values vary between each working team, as each laboratory usually has its group control. The values of the resting pressure differ in the different studies depending on the technique used. With the stationary technique and microtransducers values of $72 \mathrm{mmHg}(64-80)$ in men and of $65 \mathrm{mmHg}$ (56-74) in women have been indicated (7), whereas in other studies, also with stationary technique, can vary between $49 \pm 3 \mathrm{mmHg}$ and $58 \pm 3$ in women and between $49 \pm 3$ and $66 \pm 6$ in men (8). The normal values of the squeeze maximal pressure measured with respect to the atmospheric pressure must be greater to $60 \mathrm{mmHg}$ (7). With the stationary technique global normal values 164 of $\mathrm{mmHg}(150-178 \mathrm{mmHg})(7)$ and 173 (125-221 mmHg) (9) have been indicated, being greater in men, $193 \mathrm{mmHg}(175-211 \mathrm{mmHg})$, than in women, $143 \mathrm{mmHg}(124-162 \mathrm{mmHg}$ ) (7). The duration of the sustained squeeze pressure must be considered as the time interval in which the pressure stays $>50 \%$ of the maximal pressure (10). The normal values vary in the different studies being indicated with the stationary technique values from 32 seconds (26-38) in males and 24 seconds (20-28) in females (7).

The results of the study of rectal sensitivity are more influenced by the differences in the methodology than any other anorectal technique. De O'Campo et al (9) obtained average values for the first sensation of $18 \pm 8 \mathrm{ml}$, desire to defecate $111 \pm 56 \mathrm{ml}$, and MTV $188 \pm 53 \mathrm{ml}$. Other groups obtained the first sensation with $20-40 \mathrm{ml}$, urge sensation with $80-200 \mathrm{ml}$ and MTV with 110-480 $\mathrm{ml}$ (11). Also rectal sensitivity values differ according to sex, that the urge sensation oscillates between $60-160 \mathrm{ml}$ in women and 70-190 in men and MTV in 90-270 $\mathrm{ml}$ in women and 140-270 $\mathrm{ml}$ in men (12). Although expert and professional organizations recommend the use of the anorectal manometry (13), some authors question its utility since sensitivity and specificity are not superior to that found in the rectal digital examination $(14,15)$.

The aim of the present study is to evaluate if differences in the demographic and manometric parameters obtained from the anal canal pressures and the sensorial threshold exist in patients with AI, CC and healthy subjects that may increase the risk of AI. Also to determine if there are differences in the parameters indicated according to the type of AI.

\section{MATERIAL AND METHODS}

\section{Criteria of selection and clinical evaluation}

The definition of AI was considered as previously expressed (2) and functional CC was defined according to the definition accepted in the Rome III criteria (4).

The patients included in the group of AI where those that referred the symptoms mentioned in the previous definition which had not received any previous treatment, medical, biofeedback or surgical, for AI. AI patients were subdivided according to the type of AI in urge, passive and mixed.

The patients included in the constipation group were those who fulfilled at least two of the indicated Rome III criteria. Those patients included before 2006 fulfilled Roma II criteria previously and they were later adapted to Roma III criteria.

Fifteen healthy subjects older than 18 years were included in the control group and they did not present neither intestinal symptoms (pain, constipation or diarrhoea), nor ano-rectal disorders or surgery.

In all patients, both with $\mathrm{AI}$ and $\mathrm{CC}$, organic disease was excluded by colonoscopy/sigmoidoscopy and barium enema, as well as thyroid hormones study, celiac disease, stool culture and the study of parasites. In addition, other tests performed were individualized for each pa- 
tient (biopsies of colon, TAC, abdominal ultrasound, etc.). The patients, in who bowel inflammatory disease or any other organic cause of FI was demonstrated in the colonoscopy or barium enema, were excluded from the study. Those patients with a lack of collaboration for the suitable accomplishment of the ano-rectal functional study were not included either.

All the participants were informed of the characteristics of the study and gave their consent to participate in it. The study was approved by the Hospital Ethical Committee.

\section{Participants}

One hundred thirty patients were, included from March of 2004 to January of 2008 both inclusively they, were prospectively studied of which 94 were shown to present AI and 36 functional CC. Also 15 healthy subjects were included in the study, with a minimum age of 18 that served as the control group. Patients with AI and $\mathrm{CC}$ that were studied in the mentioned period without fulfilling the selection criteria were excluded.

\section{Evaluation of the ano-rectal function}

\section{Ano-rectal manometry: pressures and anal canal length}

Anal canal pressures were obtained with a computerized system water-perfused manometry system with a pneumohydraulic pump and a perfusion rate of 0,2 $\mathrm{ml} / \mathrm{min}$. A 4 sensors radially oriented polyvinyl probe and a polygraph (PC polygraph Medical Synectics, Stockholm; Sweden) were used. Stationary pull-through technique was performed to obtain the anal canal pressures. The mean resting pressure was obtained considering the difference between the intrarectal pressure and the maximum anal sphincter pressure at rest registered in the 4 sensors and the squeeze maximum pressure (SMP) as the difference between the intra-rectal pressure and the maximal pressure registered during the squeeze manoeuvre in the 4 sensors of registry. The squeeze pressure duration (SPD) was considered as the time interval, in seconds, during which the subject can maintain a squeeze pressure at or above $50 \%$ of the MSP (10).

The anal canal length (ACL) was defined as the length as the basal pressure exceeds the rectal pressure in more than $5 \mathrm{mmHg}(10)$.

\section{Study of the rectal sensorial threshold}

For the evaluation of rectal sensation the same equipment indicated previously was used but with a probe with
4 sensors separated $1 \mathrm{~cm}$ spirally oriented with a balloon at the end of it (Symmed).

Distensions of the balloon by means of the phasic intermittent technique were made, maintaining the balloon inflated during 30 second and deflating it later completely. Later from a resting period between 20-30 seconds the balloon was inflated again to the following volume (14). The volume of initial inflation was $20 \mathrm{cc}$. The patient was asked to advice at what point he noticed the first sensation, urge sensation and maximum tolerated volume (MTV) or pain (5). The volume of distension in each one of the described sensorial thresholds was registered.

\section{Statistical analysis}

Descriptive analyses of the mentioned variables, qualitative and quantitative were made. The qualitative variables analyzed by means of absolute frequency and percentage, whereas the quantitative variables studied through the mean \pm standard deviation (sd), median, minimum, maximum, and percentiles.

In order to make the comparisons between groups of patients with AI, CC and healthy subjects the test of Kruskal-Wallis for independent data was used, in the case of continuous variables. In case of finding statistical significance the test of Mann-Whitney for the comparison by pairs was used and, in the case of discrete variables the chi-square test. By a multinomial logistic regression model the independent variables for $\mathrm{AI}$ and CC compared to the control group were analysed, and the relative risk of them was obtained. By a binomial logistic regression, considering suffering or not AI, the independent variables were calculated and sensitivity, specificity and positive predictive and negative predictive values to predict AI. The significance level was $5 \%$. The analyses were made by means of statistical program SPSS 12,0 .

\section{RESULTS}

\section{Description of the studied groups}

The control group was formed by 15 subjects, 7 men and 8 women, with an average of age of 35.3 years (rank 50-21, sd 9.7).

The group with $\mathrm{CC}$ was constituted of 36 patients, 5 men and 31 women. The average age of the group was of 40.7 years (rank 73-18 sd 17.1).

The group with FI formed 94 patients, 24 men and 70 women, diagnosed with FI of different degrees, with an average age of 53.9 years (rank 80-18 sd 13.7 years).

Sixty two of the 94 patients $(66 \%)$ had urge FI, passive FI in $11(11.7 \%)$ and mixed in $21(22.3 \%)$. 


\section{Comparisons between the groups}

Age. There were statistically significant differences between the groups with respect to the age $(\mathrm{p}<0,001)$. In particular, the age of the AI group was higher than the control group $(\mathrm{p}<0,001)$ and the group with $\mathrm{CC}(\mathrm{p}<$ $0,001)$. There were no differences between the group with CC and the control group ( $p=0.391)$ (Table I).

Sex. Statistically significant differences in the distribution of sexes were found according to the groups $(\mathrm{p}=$ 0.046 ); whereas in the control group men and women were practically distributed the same, in the other two groups the number of women was superior to the one of men. There were no differences between the group with $\mathrm{AI}$ and the group with CC $(\mathrm{p}=0.154)$ (Table I).

Parameters of manometry. Manometry data of the three groups are expressed in table 1 . The values of the control group were: resting pressure: $91,6 \pm 23,7 \mathrm{mmHg}$ (52-135); anal canal length: $3,8 \pm 0.6 \mathrm{~cm}$ (3-5); squeeze maximum pressure: $193,0 \pm 60,9 \mathrm{mmHg}$ (88-317); duration of sustained contraction $29,9 \pm 10.3 \mathrm{~s}(14-43,5)$; first sensation $22,7 \pm 7.0 \mathrm{ml}(20-40)$; urge $88,0 \pm 12.6 \mathrm{ml}(60-$ $100)$; maximum tolerated volume $166,7 \pm 44.5 \mathrm{ml}(120$ 280 ). Overlapping of the values in the 3 groups was observed (Fig. 1). $81.7 \%$ of the patients with AI had 2 or more parameters altered with respect to the minimum values (or maximum, according to the case) of the control group.

Resting pressure. $45.2 \%$ of the patients with AI had an inferior resting pressure to the minimum of the control group $(52 \mathrm{mmHg})$. There were statistically significant differences between the groups with respect to the RP ( $p$ $<0,001)$. In particular, the resting pressure of AI group was inferior to the one of the control group $(\mathrm{p}<0,001)$ and $\mathrm{CC}$ group $(\mathrm{p}<0,001)$.

There were no differences between the group with $\mathrm{CC}$ and the control group $(\mathrm{p}=0.627)$.

Anal canal length (ACL). $15.1 \%$ of the patients with AI had an inferior ACL to the minimum of the control group $(3 \mathrm{~cm})$. There were statistically significant differences between the groups with respect to the ACL ( $p<$ $0,001)$. In particular, the ACL of the AI group was inferior to the one of the control group $(p<0,001)$ and the $C C$ group $(\mathrm{p}<0,001)$. There were no differences between the $\mathrm{CC}$ group and the control group $(\mathrm{p}=0.217)$.

Squeeze maximal pressure (SMP). $20.4 \%$ of the patients with AI had an inferior SMP to the minimum of the control group $(88 \mathrm{mmHg})$. There were statistically significant differences between the groups with respect to the SMP $(p=0.003)$. In particular, the SMP of the AI group was inferior to the one of the control group $(\mathrm{p}=0.003)$ and to the one of the CC group $(\mathrm{p}=0.028)$. There were no differences between the $\mathrm{CC}$ group and the control group $(\mathrm{p}=0.111)$.

Squeeze pressure duration (SPD). $18.5 \%$ of the patients with AI had an inferior SPD to the minimum of the control group. There were no statistically significant differences between the groups with respect to the SPD ( $p=$ 0.363 ).

First sensation. $7.6 \%$ of the patients with AI had the first sensation volume threshold higher than the minimum of the control group $(40 \mathrm{ml}$.). There were differences between the groups with respect to the volume of the first sensation threshold $(\mathrm{p}=0.019)$. In particular, first sensation in the control group was lower to the one of the AI group ( $p=0.047)$ and to the one of the CC group ( $\mathrm{p}=0.008)$. There were no differences between the $\mathrm{CC}$ and $\mathrm{AI}$ groups $(\mathrm{p}=0.098)$.

Urge sensation. $25.3 \%$ of the patients with AI had an inferior urge sensation volume to the minimum of the control group $(60 \mathrm{ml}$.). There were statistically significant differences between the groups with respect to urge sensation $(p<0,001)$. In particular, the volume threshold for urge was inferior to the control group $(p<0,001)$ and to the $\mathrm{CC}$ group $(\mathrm{p}<0,001)$. There were no differences between the $\mathrm{CC}$ and control groups $(\mathrm{p}=0.551)$.

Maximum tolerated volume (MTV). $39.6 \%$ of the patients with AI had an inferior MTV to the minimum of the

Table I. Demographic and manometric parameters of the 3 groups

\begin{tabular}{|c|c|c|c|c|}
\hline Parameters & Al & $C C$ & Control & Signification \\
\hline Age (years) & $53.9+13.7$ & $40.7+17.1$ & $35.3+9.7$ & $p<0.001$ \\
\hline$\overline{\mathrm{RP}}(\mathrm{mmHg})$ & $57.7+27.1$ & $87.9+28.9$ & $91.6+23.7$ & $p<0.001$ \\
\hline$\overline{\mathrm{ACL}}(\mathrm{cm})$ & $3.1+0.6$ & $3.6+0.5$ & $3.8+0.6$ & $p<0.001$ \\
\hline$\overline{\mathrm{FS}}(\mathrm{ml})$ & $31.1+18.9$ & $35.6+18.0$ & $22.7+7.0$ & $p<0.05$ \\
\hline$\overline{U S}(\mathrm{ml})$ & $66.3+22.6$ & $98.9+46.6$ & $88.0+12.6$ & $p<0.001$ \\
\hline$\overline{\mathrm{MVT}}(\mathrm{ml})$ & $135.2+53.7$ & $172.2+63.1$ & $166.7+44.5$ & $p<0.001$ \\
\hline
\end{tabular}

Al: anal incontinence; CC: chronic constipation; RP: resting pressure; ACL: anal canal length; SMP: squeeze maximum pressure; SPD: squeeze pressure duration; FS: first sensation; US: urge sensation; MTV: maximum tolerated volume. 

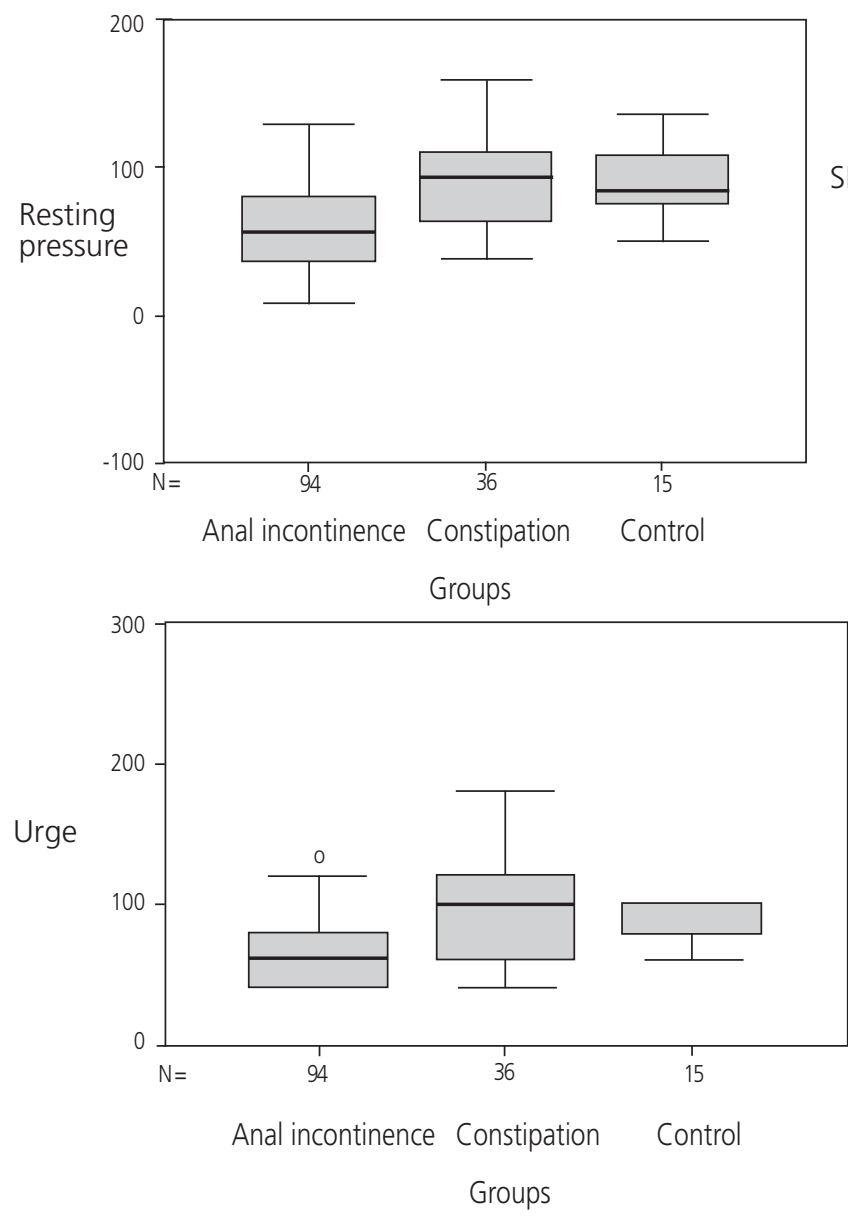
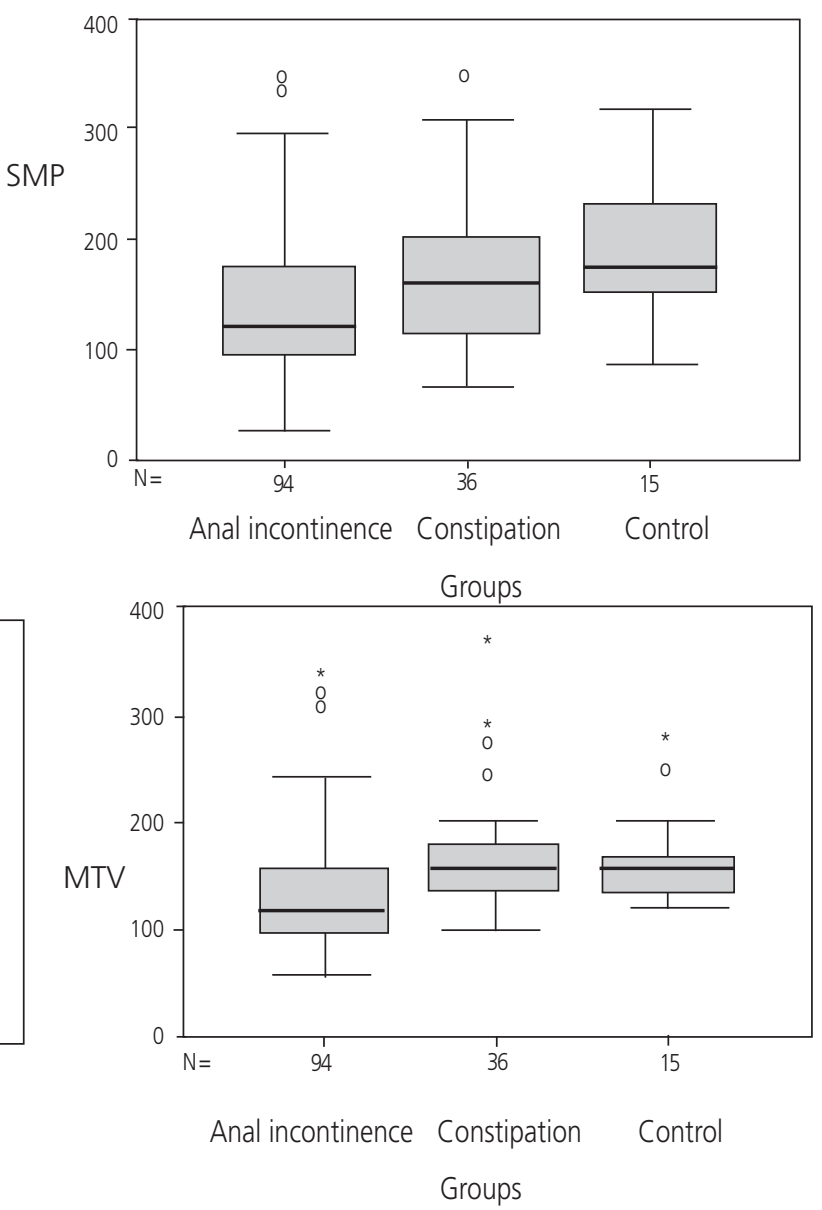

Fig. 1. Values of the anal canal pressures and sensorial threshold (Urge sensation and MTV) of the 3 groups studied. This expresses the median, the 25 and 75 percentiles and the extreme values. The values overlap in the three groups is observed. SMP: squeeze maximum pressure; MTV: maximum tolerated volume.

control group $(120 \mathrm{ml})$. There were statistically significant differences between the groups with respect to the MTV (p $<0,001)$. In particular, the MTV in the group AI was lower than the one of the control group $(\mathrm{p}=0.002)$ and $\mathrm{CC}$ group $(\mathrm{p}<0,001)$. There were no differences between the group with CC and the control group ( $\mathrm{p}=0.924)$.

Multivariate analysis (independent variables in AI and $C C$ with respect to the control group). Age (RR 1.07; IC95\% (1.02-1.13); $\mathrm{p}=0.006)$, resting pressure (RR 0.96; IC95\% (0.94-0.99); $\mathrm{p}=0.013)$, first sensation volume threshold (RR 1.12; IC (1.03-1.22); $\mathrm{p}=0.006)$, and urge volume threshold (RR 0.96; IC95\% (0.93-0.98); $\mathrm{p}=$ 0.001 ) were independent variables for the AI, so that the increase of the age, the diminution of the resting pressure, the increase of the volume for the first sensation and the diminution of the urge volume increased the relative risk of AI. In the case of the constipation only sex (RR 8.8; IC95\% (1.71-46.06); $\mathrm{p}=$ the 0.009$)$ and volume for first sensation (RR1.09; IC95\% (1.01-1.19); $p=0.02$ ) were independent variables when comparing with the group control, so that, female sex and the increase of the volume for the first sensation increase the relative risk of CC (Table II).

The probability of having or not AI with the proposed model (independent variables: age, resting pressure and urge sensation), have a sensitivity of $87 \%$, a specificity of $69 \%$ a PPV of $84 \%$ and a PNV of $74 \%$. The area under curve ROC was 0.87 .

Manometry parameters and distribution by sex. Manometríc data with regard to the distribution by sexes are expressed in table III. When considering jointly the three groups, SMP was significantly smaller in women than in the men $(p=0,001)$, and also there was a tendency for MVT to be smaller in women $(p=0.046)$. When analyzing the results in each group, the SMP was significantly smaller in women with AI than in men $(p=0,004)$, this tendency was also observed in the $\mathrm{CC}$ and the control groups.

Type of AI and manometry parameters. There were no statistically significant differences between the AI groups 
Table II. Risk factors for $\mathrm{Al}$ and $\mathrm{CC}$ in regard to control group

\begin{tabular}{|c|c|c|c|c|c|}
\hline Group & $z$ & Std. Err. & $R R$ & $95 \% \mathrm{Cl}$ & Signification \\
\hline $\begin{array}{l}\text { Incontinence } \\
\text { Age } \\
\text { Sex } \\
\text { RP (mmHg) } \\
\text { FS (ml) } \\
\text { US (ml) } \\
\end{array}$ & $\begin{array}{c}2.77 \\
1.20 \\
-2.49 \\
2.72 \\
-3.20\end{array}$ & $\begin{array}{l}0.03 \\
1.88 \\
0.01 \\
0.05 \\
0.01\end{array}$ & $\begin{array}{l}1.07 \\
2.48 \\
0.97 \\
1.12 \\
0.96\end{array}$ & $\begin{array}{c}1.02-1.13 \\
0.56-11.01 \\
0.94-0.99 \\
1.03-1.22 \\
0.94-0.98\end{array}$ & $\begin{array}{c}p<0.01 \\
N S \\
p<0.05 \\
p<0.01 \\
p<0.01\end{array}$ \\
\hline $\begin{array}{l}\text { Constipation } \\
\text { Age } \\
\text { Sex } \\
\text { RP }(\mathrm{mmHg}) \\
\text { FS (ml)2.26 } \\
\text { US (ml) }\end{array}$ & $\begin{array}{c}0.79 \\
2.60 \\
-0.42 \\
0.05 \\
-0.89\end{array}$ & $\begin{array}{l}0.03 \\
7.46 \\
0.01 \\
1.09 \\
0.01\end{array}$ & $\begin{array}{c}1.02 \\
8.89 \\
0.99 \\
1.01-1.19 \\
0.99\end{array}$ & $\begin{array}{c}0.97-1.07 \\
10.72-46.06 \\
0.97-1.02 \\
p<0.05 \\
0.97-1.01\end{array}$ & $\begin{array}{c}\text { NS } \\
p<0.01 \\
\text { NS } \\
\text { NS }\end{array}$ \\
\hline
\end{tabular}

LR $\operatorname{chi}^{2}(10)=86.01$; prob $>\mathrm{chi}^{2}=0.0000$; Pseudo R2 $=0.34$.

RP: resting pressure; FS: first sensation; US: urge sensation; RR: relative risk; Cl: confidence interval.

Table III. Manometry parameters with regard to sex in the $\mathbf{3}$ groups

\begin{tabular}{|c|c|c|c|c|c|c|}
\hline \multirow[t]{2}{*}{ Parameters } & \multicolumn{2}{|c|}{$A l(N=94)$} & \multicolumn{2}{|c|}{$C C(N=36)$} & \multicolumn{2}{|c|}{ Control $(N=15)$} \\
\hline & $\begin{array}{l}\text { Women } \\
(N=70)\end{array}$ & $\begin{array}{c}\text { Men } \\
(N=24)\end{array}$ & $\begin{array}{l}\text { Women } \\
(N=31)\end{array}$ & $\begin{array}{c}\text { Men } \\
(N=5)\end{array}$ & $\begin{array}{c}\text { Women } \\
(N=8)\end{array}$ & $\begin{array}{c}\text { Men } \\
(N=7)\end{array}$ \\
\hline $\mathrm{ACL}(\mathrm{cm})$ & $3.1 \pm 0.5$ & $3.3 \pm .9$ & $3.6 \pm 0.5$ & $3.4 \pm 0.5$ & $3.8 \pm 0.6$ & $3.7 \pm 0.5$ \\
\hline $\mathrm{SMP}(\mathrm{mmHg})$ & $125.6 \pm 51.7$ & $182 \pm 86.3^{*}$ & $162.3 \pm 61.2$ & $178.6 \pm 80.2$ & $172.1 \pm 44.2$ & $216 \pm 71.7$ \\
\hline $\mathrm{FS}(\mathrm{ml})$ & $28.0 \pm 11$ & $40.0 \pm 31.2$ & $34.2 \pm 18$ & $44 \pm 16.7$ & $22.5 \pm 7.1$ & $22.9 \pm 7.6$ \\
\hline US (ml) & $64.9 \pm 20.8$ & $70.9 \pm 27.4$ & $99.4 \pm 49.1$ & $96 \pm 29.7$ & $90 \pm 10.7$ & $85.7 \pm 15.1$ \\
\hline MVT (ml) & $126.3 \pm 70$ & $163.6 \pm 77.7$ & $172.3 \pm 67.9$ & $172 \pm 17.9$ & $165 \pm 35.1$ & $168.6 \pm 56.4$ \\
\hline
\end{tabular}

in any parameter of the manometry (PR, $p=0,371$; LCA, $\mathrm{p}=0,247$; PMCV, $\mathrm{p}=0,501 ; \mathrm{DCV}, \mathrm{p}=208 ; \mathrm{PS}, \mathrm{p}=$ 0,$541 ;$ HIS, $p=0,854 ;$ MVT, $p=0,116$ ) (Table IV).

\section{DISCUSSION}

Although there are established causes that can be directly responsible for triggering the appearance of AI, in most cases there are multifactor origin, being able to find some patients with ano-rectal anatomical and functional studies within normality.

A wide variety of factors exists that facilitate the appearance of AI, among them age, in such a way that although AI can affect any group of age, it is more prevalent in older patients $(16,17)$. This fact can justify the greater age found in the group of patients with AI with respect to the $\mathrm{CC}$ group and healthy subjects, being an independent risk factor, but we are conscious of the limitations imposed by not beingable to have a control group with similar ages to those of the patients with AI. In fact limited information about normal values has been published, and in most studies a healthy control group is typically composed with young subjects with an equal distribution of men and women (14).

On the other hand, the distribution by sexes of the control group homogenous, both AI and CC are more frequent in women (14), although in our study females only had an increased probability of having CC.

With respect to the manometric findings of the patients with AI: the resting pressure, ACL and SMP are diminished compared to the other groups as described by other authors $(12,14,18)$. There is also a more impaired rectal sensation. However, there is an overlap between values obtained in the AI group and the other groups, situation already referred in other studies (14). The diminution of resting pressure, the increase of first sensation and the diminution of urge volume threshold increase the risk of AI. Nevertheless, in the CC, only a greater volume for the first sensation increases the probability of it.

Therefore, the resting pressure and rectal sensitivity are important factors in the development of AI, whereas 
Table IV. Manometry parameters and Al type

\begin{tabular}{|c|c|c|c|}
\hline & $\begin{array}{l}\text { Urge Al } \\
(N=62)\end{array}$ & $\begin{array}{l}\text { Passive } A l \\
(N=11)\end{array}$ & $\begin{array}{l}\text { Mixed Al } \\
(N=21)\end{array}$ \\
\hline $\mathrm{RP}(\mathrm{mmHg})$ & $59.8 \pm 27.0$ & $48.1 \pm 23.9$ & $56.6 \pm 28.8$ \\
\hline$\overline{\mathrm{ACL}(\mathrm{cm})}$ & $3.2 \pm 0.7$ & $2.9 \pm 0.4$ & $3.2 \pm 0.5$ \\
\hline $\mathrm{SMP}(\mathrm{mmHg})$ & $139.9 \pm 60.2$ & $165.9 \pm 98.1$ & $126.3 \pm 64.7$ \\
\hline SPD (s) & $25.9 \pm 15.0$ & $34.1 \pm 15.2$ & $25.8 \pm 16.1$ \\
\hline $\mathrm{FS}(\mathrm{ml})$ & $29.4 \pm 15.7$ & $41.8 \pm 37.4$ & $30.5 \pm 12.0$ \\
\hline US (ml) & $66.9 \pm 24.7$ & $68 \pm 19.3$ & $63.8 \pm 17.5$ \\
\hline$\overline{\mathrm{MVT}}(\mathrm{ml})$ & $132.8 \pm 48.7$ & $178 \pm 87.2$ & $121.9 \pm 38.4$ \\
\hline
\end{tabular}

in $\mathrm{CC}$ the pressures do not seem to be as important as rectal sensitivity. According to our model, AI probabilities increase with age and the alterations in the described manometric parameters with sensitivity of $87 \%$ and PPV of $84 \%$ but with specificity of only $69 \%$.

In regard to AI type, some studies suggest that passive AI correlated with lower resting pressure (19), but there are perfectly continent subjects with low basal pressures, the reason why, the significance of the sphincter resting pressure in the pathophysiology of AI must be considered in combination with other functional findings (6). Urge AI usually is due to functional or anatomical alteration of the external anal sphincter (EAS) and/or to the incapacity of the rectum to retain stools (20), and it correlates with a lower squeeze contraction (19). In this study we have not demonstrated that the type of AI is associated with significant differences in the anal canal pressures, probably caused by the small number of patients in the passive AI group. Nevertheless, the correlation between anal canal pressures and incontinence are not exact due to the wide rank of normal values and the contribution of other factors in the continence (6).

The inability to maintain the voluntary contraction during 10 seconds can mean a reduction in the number of tonic fibbers and can favour the incontinence, in spite of a good SMP (21). We have neither found differences in the SPD between patients with AI regarding the type of AI nor with respect to the other studied groups, as previous authors have described (22).

ACL is significantly smaller in patients with AI with regard to the patients with $\mathrm{CC}$ and the control group, agreeing with reports in other studies (23), although the clinical meaning of this measurement is not clear.

The extent of the results of the manometry with regard to sex, a diminution in the SMP in women with respect to men in patients with AI was observed, this situation already referred to other authors and that also occurs in healthy subjects $(7,9)$.
Although the sphincter dysfunction is considered the most important factor in AI, sensitivity and rectal adaptation plays a role in it (24). The response of EAS to the rectal distension is crucial to maintain the continence and is closely related to the sensorial function and rectal compliance (21). Nevertheless, the rectal perception and the adaptation to the distension are very heterogeneous in patients with AI. These discrepancies can be in relation, among other factors, with methodological aspects (25).

The threshold volume for the first sensation in patients with AI can be diminished, normal or increased (26), as in the present study. Nevertheless, it has been indicated that in constipated patients it is increased, agreeing with our results (27). Rectal hypersensitivity contributes to AI independently of the patients' age (28), as we confirmed in our study as the urge volume threshold diminution is an independent risk factor for AI. A diminished MTV in patients with $\mathrm{AI}$ with regard to $\mathrm{CC}$ and the control groups was also found. A low MTV reflects an alteration in rectal compliance, studied by means of barostat, in 2 out of 3 patients (25). The fact that there were no endoscopic injuries in any of the patients makes it less probable that the sensorial abnormalities found must be related to alterations of the rectal wall, and probably, they were related to the existence of some dysfunction in the motor sensory innervations'.

Although manometry together with other anorectal functional studies orients us towards the cause of AI $(29,30)$, some authors consider that it should not to be used on a routine basis by his low sensitivity and specificity (14). With this fact it is necessary to add the lack of uniformity in the equipment and the accomplishment of the technique as reasons why the comparison of the results between different centres is difficult. As a consequence, it is important that each laboratory has its own reference values (6). This fact, also could explain the discrepancies found in different studies.

In spite of these limitations, we considered that the manometry does contribute in giving a more global vision of the pathophysiology of AI, as $82 \%$ of the patients with AI had two or more altered parameters in the manometry, confirming that $\mathrm{AI}$ is a multifactorial disorder. In addition, the diminution of the resting pressure and rectal hypersensitivity increases the probability that a patient suffers AI, data that we assessed from the manometric study.

In conclusion, the greater age, the diminution in the resting pressure and the urge volume threshold are risk factors for the development of AI. Therefore, older patients and/or with alteration in the anal canal resting pressure and rectal sensitivity have a higher probability of presenting AI. These parameters, obtained from the manometry, allow us to understand the pathophysiology of AI, considering the limitations that the technique presents. 


\section{REFERENCES}

1. Norton C, Christiansen J, Butler U, Harare D, Nelson RL, Pemberton J, et al. Anal incontinence. Plymbridge Distributors Ltd. 2002. p. 985-1044.

2. Sentovich SM, Rivela LJ, Blatchford GJ, Christensen MA, Thorson AG. Patterns of male fecal incontinence. Dis Colon Rectum 1995; 38: 281-5.

3. Macmillan AK, Merrie AE, Marshall RJ, Parry BR. The prevalence of fecal incontinence in community-dwelling adults: a systematic review of the literature. Dis Colon Rectum 2004; 47: 1341-9.

4. Drossman D. The functional gastrointestinal disorders and the Rome III process. Gastroenterology Gastroenterology 2006; 130: 1377-90.

5. Husni-Hag-Ali R, Gomez Rodriguez BJ, Mendoza Olivares FJ, Garcia Montes JM, Sachez-Gey Venegas S, Herrerias Gutierrez JM. Measuring colonic transit time in chronic idiophatic constipation. Rev Esp Enferm Dig 2003; 95: 186-90.

6. Scott SM, Gladman MA. Manometric, sensorimotor, and neurophysiologic evaluation of anorectal function. Gastroenterol Clin North Am 2008; 37: 511-38.

7. Rao SS, Hatfield R, Soffer E, Rao S, Beaty J, Conklin JL. Manometric tests of anorectal function in healthy adults. Am J Gastroenterol 1999; 94: 773-83.

8. Diamant NE, Kamm MA, Wald A, Whitehead WE. AGA technical review on anorectal testing techniques. Gastroenterology. Gastroenterology 1999; 116: 735-60.

9. De Ocampo S, Remes-Troche JM, Miller MJ, Rao SS. Rectoanal sensorimotor response in humans during rectal distension. Dis Colon Rectum 2007; 50: 1639-46.

10. Rao SS, Azpiroz F, Diamant N, Enck P, Tougas G, Wald A. Minimum standards of anorectal manometry. Neurogastroenterol Motil 2002; 14: 553-9.

11. Kouraklis G, Andromanakos N. Evaluating patients with anorectal incontinence. Surg Today 2004; 34: 304-12.

12. Chan CL, Lunniss PJ, Wang D, Williams NS, Scott SM. Rectal sensorimotor dysfunction in patients with urge faecal incontinence: evidence from prolonged manometric studies. Gut 2005; 54: 1263-72.

13. Barnett JL, Hasler WL, Camilleri M. American Gastroenterological Association medical position statement on anorectal testing techniques. American Gastroenterological Association. Gastroenterology 1999; 116: 732-60

14. Raza N, Bielefeldt K. Discriminative value of anorectal manometry in clinical practice. Dig Dis Sci 2009; 54: 2503-11.

15. Dobben AC, Terra MP, Deutekom M, Gerhards MF, Bijnen AB, Felt-Bersma RJ, Janssen LW, Bossuyt PM, Stoker J. Anal inspection and digital rectal examination compared to anorectal physiology tests and endoanal ultrasonography in evaluating fecal incontinence. Int J Colorectal Dis 2007; 22: 783-90.
16. Bharucha AE, Zinsmeister AR, Locke GR, Seide BM, McKeon K Schleck CD, et al. Risk factors for fecal incontinence: a populationbased study in women. Am J Gastroenterol 2006; 101: 1305-12.

17. Wang JY, Patterson TR, Hart SL, Varma MG. Fecal Incontinence: Does Age Matter? Characteristics of Older vs. Younger Women Presenting for Treatment of Fecal Incontinence. Dis Colon Rectum 2008; 51: 426-31.

18. Deutekom M, Dobben AC, Terra MP, Engel AF, Stoker J, Bossuyt PM, Boeckxstaens GE. Clinical presentation of fecal incontinence and anorectal function: what is the relationship? Am J Gastroenterol 2007; 102: 351-61.

19. Engel AF, Kamm MA, Bartram CI, Nicholls RJ. Relationship of symptoms in faecal incontinence to specific sphincter abnormalities. Int J Colorectal Dis 1995; 10: 152-5.

20. Rao SS, Ozturk R, Stessman M. Investigation of the pathophysiology of fecal seepage. Am J Gastroenterol 2004; 99: 2204-9.

21. Azpiroz F, Enck P, Whitehead WE. Anorectal functional testing: review of collective experience. Am J Gastroenterol 2002; 97: 232-40.

22. Telford KJ, Ali AS, Lymer K, Hosker GL, Kiff ES, Hill J. Fatigability of the external anal sphincter in anal incontinence. Dis Colon Rectum 2004; 47: 746-52.

23. Prott G, Hansen R, Badcock C, Kellow J, Malcolm A. What is the optimum methodology for the clinical measurement of resting anal sphincter pressure? Neurogastroenterol Motil 2005; 17: 595-9.

24. Athanasakos EP, Ward HC, Williams NS, Scott SM. Importance of extrasphincteric mechanisms in the pathophysiology of faecal incontinence in adults with a history of anorectal anomaly. Br J Surg 2008; 95: 1394-400.

25. Siproudhis L, El Abkari M, El Alaoui M, Juguet F, Bretagne JF. Low rectal volumes in patients suffering from fecal incontinence: what does it mean?. Aliment Pharmacol Ther 2005; 22: 989-96.

26. Salvioli B, Bharucha AE, Rath-Harvey D, Pemberton JH, Phillips SF. Rectal compliance, capacity, and rectoanal sensation in fecal incontinence. Am J Gastroenterol 2001; 96: 2158-68.

27. Liu TT, Chen CL, Yi CH. Anorectal manometry in patients with chronic constipation: a single-center experience. Hepatogastroenterology 2008; 55: 426-9.

28. Lewicky-Gaupp C, Hamilton Q, Ashton-Miller J, Huebner M, DeLancey JO, Fenner DE. Anal sphincter structure and function relationships in aging and fecal incontinence. Am J Obstet Gynecol 2009; 200: 559 -5.

29. Muñoz Yagüe T, Álvarez Sánchez V, Ibanez Pinto A, Solís-Herruzo JA. Clinical, anorectal manometry and surface electromyography in the study of patients with fecal incontinence. Rev Esp Enferm Dig 2003; 95: 629-34.

30. García-Olmo DI. Pascual-Migueláñez I. A sonograph in the proctology clinic - an aid to the "learned finger. Rev Esp Enferm Dig 2010; 102: 1-6. 